\title{
Optimization and efficiency of toolpath generation in CAD/CAM system
}

\author{
Tomáš Dodok ${ }^{1^{*}}$, and Nadežda Čuboňová ${ }^{1}$ \\ ${ }^{1}$ University of Žilina, Faculty of Mechanical Engineering, Department of Automation and Production \\ systems, Univerzitná 1, 01026 Žilina, Slovak Republic
}

\begin{abstract}
The optimization has an important role in machining processes preparation of NC programs. The article deals with the possibilities of the optimization using at utilization of the NC tool paths in CAD/CAM systems. The experiments deal with the possibility of optimization option in concrete $\mathrm{CAD} / \mathrm{CAM}$ system. Particularly were compared optimized toolpaths from CAD / CAM system Creo with toolpaths optimized in an optimization program Optimizer based on genetic algorithms.
\end{abstract}

\section{Introduction}

Machining optimisation is a very complex process, which is a prerequisite for high-quality solutions of a technological process in a CAD/CAM system. The modern concept of $\mathrm{CAD} / \mathrm{CAM}$ systems enables optimising the process by a number of criteria. Optimisation can be based for example on a semi-finished product. The semi-finished product in a $\mathrm{CAD} / \mathrm{CAM}$ system is gradually updated (modified) during the design and simulation of the machining process. Each following operation includes machining of the remaining material only. This means elimination of unnecessary and inefficient movements and actions. The process of creating a machining process in $\mathrm{CAD} / \mathrm{CAM}$ systems can be optimised also for example in terms of the tool shape and dimensions and clamps or mandrels. The $\mathrm{CAD} / \mathrm{CAM}$ system then optimises the machining strategy with regard to undercut or collision of the tool with a workpiece or collision with other components in the machining area or with other components of the CNC machine (desk, preparations, mandrel, etc.). Technological modules of advanced CAD/CAM systems include also a wide range of possible definitions of the shape of tool, clamps and mandrel, as well as of other components of the machining device (headstock, etc.).

Computer aided optimisation of machining processes (CAM - computer-aided manufacturing) utilises software applications where the method of performance is usually carried out using additional modules (optimisation programs). Optimisation programs enable to optimise, in the machining process, especially tool paths, cutting parameters, NC programs, etc.. CAD/CAM systems for example enables to perform analysis of a section of the generated NC program and display the results of optimisation [8]. Then, the optimised NC program can be carefully studied, individual feed values are clearly displayed in

* Corresponding author: tomas.dodok@ffstroj.uniza.sk 
different colours, with the possibility to individually perform analysis of these tool path segments. It is possible to generate also tables with time savings that show the original length and the machining time before and after optimisation. Using optimisation software for machining enables to achieve, first of all, shortened time of machining, increased tool life (durability), increased machining efficiency, machining stability (jitter elimination), etc. In terms of integrating an optimisation program to a CAM system, the currently existing optimisation programs can be divided into three basic groups. Separate optimisation programs (elaborated in one of the programming languages), Collaborating optimisation programs (NC program created in a CAM system is first analysed and then optimised), Optimisation programs integrated in CAM systems (include an additional or integrated module for optimisation directly in a CAM or CAD/CAM system). [7].

Development and creation of an optimisation module as a technological tool within a CAD/CAM system requires comprehensive knowledge of experts, specialists and programmers from various fields. Creating a separate optimisation program utilises mathematical methods of determining, for example, cutting parameters. The programs are usually elaborated in one of the programming languages, such as Visual Basic, Delphi, etc. The outcome of such programs are the generated optimised cutting parameters, or toolpath modified in a NC program either directly by an optimisation software or they must be modified manually by the user. These types of optimisation software are usually addressed at university workplaces.

Semrád and Cernan [1] also dealt with the problem of comparing the toolpaths created for the Creo drilling strategies. The present article deals with the comparison of toolpath optimization options in the CAD / CAM system Creo and in a separate Optimizer Optimizer program based on genetic algorithms.

\section{Experiments}

Drilling holes on a CNC milling machine is a simple operation. However, there are cases where it is necessary to drill a large number of identical holes on one component. For example, printed circuit boards, in the development of electronic devices, but it can be encountered in many other areas. The reason why this problem is so often solved in the production of circuit boards is that the drilling process itself is very short. Movement of the tool out of the contact with the machined surface presents an essential part of the production time. The second reason is the number of holes, because to find the optimal path for more than 20 points becomes almost unrealistic task under conditions of common practice [7]. In such cases, it depends on the order in which the holes are drilled. Therefore, it is necessary to choose a drilling sequence that ensures a minimum machining time - i.e. the toolpath is optimized.

Local milling is an operation which is performed after previous operation of volume milling with a larger diameter tool. In places where a larger diameter tool could not remove the material, a smaller-diameter tool is used; this operation is called local milling.

\subsection{Possibilities of optimization of drilling process and local milling}

Experiment of drilling process was performed on one component (Fig.1 (a)). Toolpaths for experimental component were generated in the Creo CAD/CAM system and included the use of a strategy for drilling a group of holes and local milling.

In experiments for local milling strategies, surfaces with different rounding diameters were used. The comparison and subsequent optimization of the toolpath consisted of several steps. 
a)

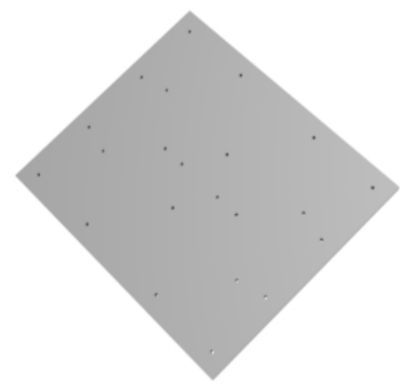

c)

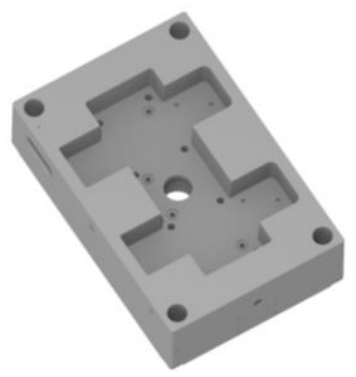

b)

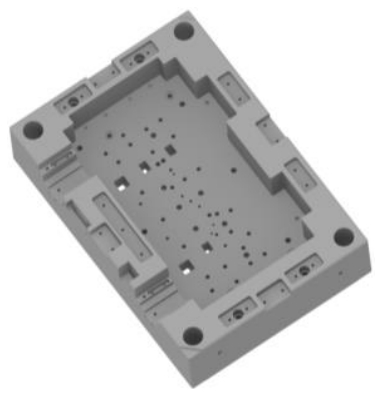

d)

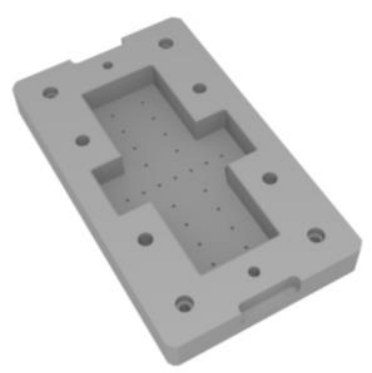

Fig. 1. 4 types of components for drilling process

First, in the $\mathrm{CAD} / \mathrm{CAM}$ system Creo at machining process, the following types of drill path settings were used in each strategy: Shortest (a), One Direction (b), Pick Order (c), Spiral (d) (Figure 2).

a)

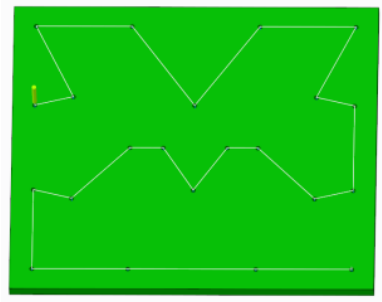

c)

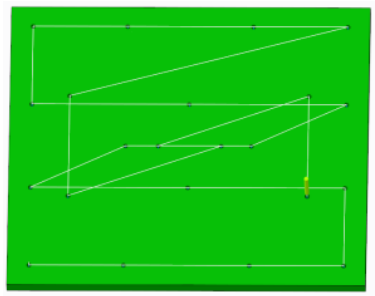

b)

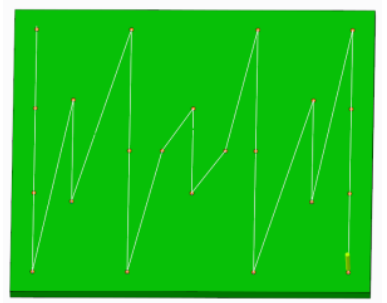

d)

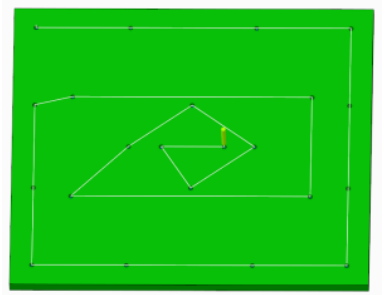

Fig. 2. Strategy: Shortest (a), One Direction (b), Pick Order (c), Spiral (d)

The second step in comparing the generation of toolpaths was to use a separate optimization program based on genetic algorithms [3]. A separate optimisation program called Toolpath Optimizer was designed to optimise the process of drilling and local milling. This software was used by authors to optimize toolpaths generated mainly by Wildfire (lower version of Creo). Wildfire does not allow you to generate the shortest toolpaths and optimize the machining process. The results of research into toolpath optimization using this software have been previously published in books, magazines and conferences [2]. 
A tool path for drilling process was generated with "shortest" strategy in the system Creo then transformed into the CL data file and, subsequently, loaded into Toolpath Optimizer. Fig. 3a shows a tool path of the drilling process the one generated by the system Creo, and Fig. $3 \mathrm{~b}$ shows the optimized tool path generated with the Toolpath Optimizer software.

a)

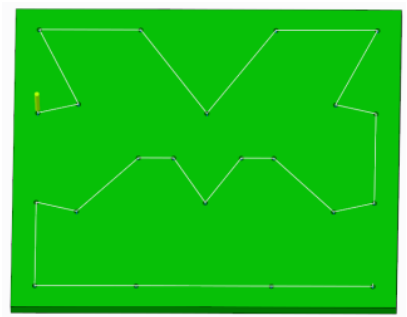

b)

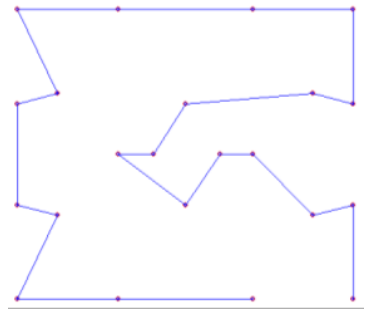

Fig. 3. a) tool path of the drilling process generated by the system Creo

b) optimized tool path generated by the application Toolpath Optimizer

Based on the experiments performed, it can be concluded that the generated toolpath for drilling operations based on current strategies in Creo is comparable (in some cases shorter) than the optimized toolpath output from the Optimizer software.

Consequently, the use of Toolpath Optimizer is no longer relevant to drilling operations. The genetic algorithm in the Toolpath Optimizer should be adapted to the current conditions of the generated CL data from Creo.

Despite the above, using Toolpath Optimizer for local milling is still important, as confirmed by the results from the experiments below. Experiments of local milling process were performed on 3 types of components (Fig.1 (b) (c) (d)). Toolpaths for experimental components were generated in the Creo CAD/CAM system and included the use of local milling strategies, surfaces with different rounding diameters were used (Fig 4). The local milling process is, from the point of view of tool rapid traverses, similar to the process of drilling.

a)

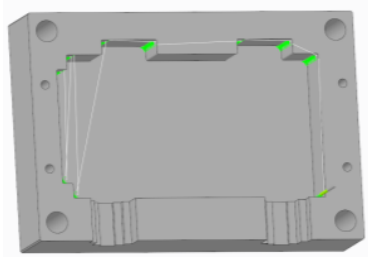

b)

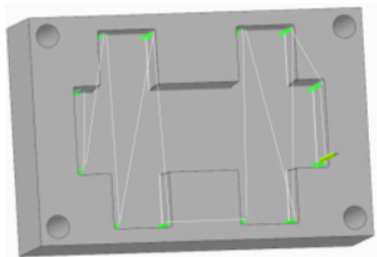

c)

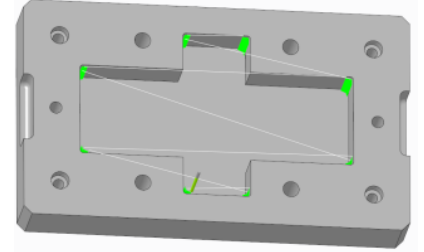

Fig. 4. Toolpaths for experimental components generated in the Creo

Fig. 5 shows a simple example of tool path optimization process using Local Mill sequence in CAD/CAM system Creo, at Fig.5a is an original non-optimized tool path generated by the system Creo; Fig.5b shows the same tool path optimized by Toolpath Optimizer. Graphical flow of the optimization process at the milling operation shows the Fig.6. 
a)

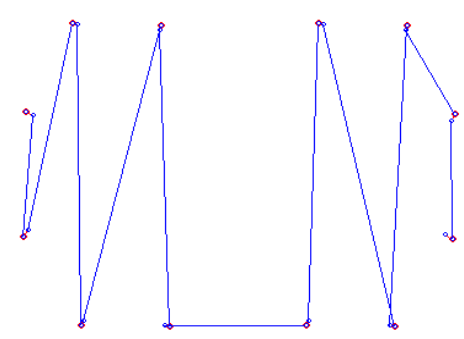

b)

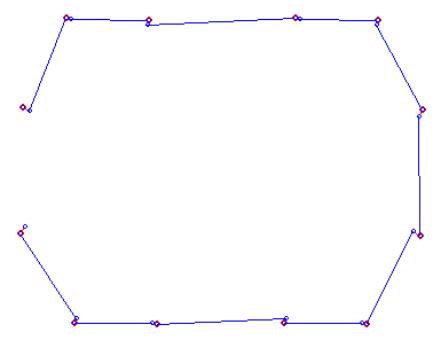

Fig. 5. a) tool path of the local milling generated by the system Creo

b) optimized tool path generated by the application Toolpath Optimizer

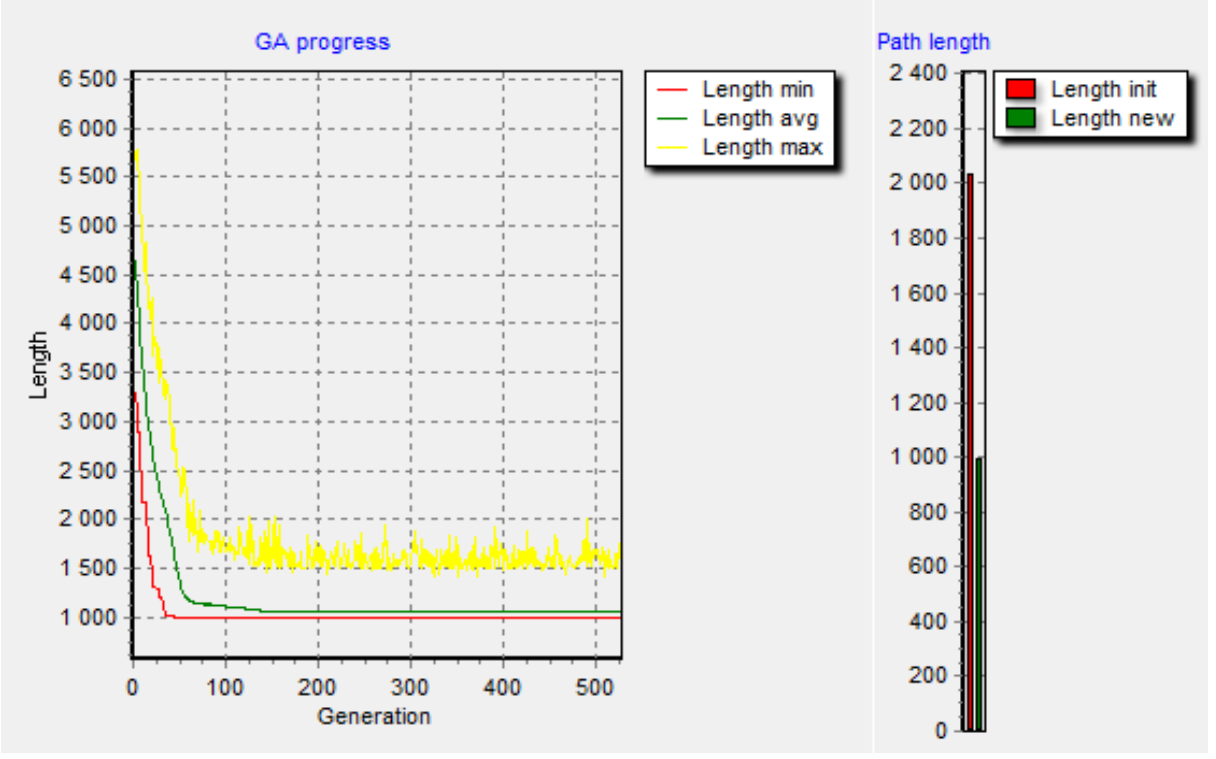

Fig. 6. Graphical flow of the optimization process at the milling operation

Optimization process in the Toolpath Optimizer is started with confirmation of the selection sequence. Its graphical flow is shown in two tabs (Fig. 6). One shows the best path in each step of the evolutionary process (Path length) and the other gives graphical information about the evolutionary process (GA process). Path length graphically displays the original length of a toolpath generated from the CL data file (Length init) and a new optimized path length (Length new) generated by GA. When the evolutionary process is completed, it is possible to compare the length of the new and original path, to compare the optimized path (Fig. 6), to decide whether the result meets the requirements or to repeat the evolutionary process

\section{Conclusion}

To successfully address an optimisation problem, we must know optimisation methods and appropriately select the methods we want to deploy to solve the problem in question. Although some methods resemble one another due to their work processes, they may not be equally suitable for solving the given task. Improper use of a method can reduce the resulting effect of its work, it can even lead to obtaining false results. Most of the common 
$\mathrm{CAM}$ and $\mathrm{CAD} / \mathrm{CAM}$ systems are not using any optimization technique, or are using some kind of linear mathematic based technique for solving this task due to the computing time $[2,4]$. GA due to their efficiency can solve mentioned problems in few minutes instead of a long time (hours, days) with very good result. The genetic algorithm which forms the core of the Toolpath Optimizer proved to be a highly effective means of optimization.

This optimization module may be used either directly or it can easily be modified in compliance with users' requirements. For example, it is possible to change the module of input and output data, which currently works only with the CL data field of CAD/CAM system Creo. The experiments were created to optimize processes of drilling and local milling. The result may be considered highly satisfying for milling process, for drilling process the genetic algorithm in the Toolpath Optimizer should be adapted to the current conditions of the generated CL data from Creo.The results of these experiments show that genetic algorithms are a simple and effective method for solving complex optimization problems. From the practical point of view, the application Toolpath Optimizer can be used in the pre-production phase with the aim to increase productivity and reduce production costs.

This article was made under the support of KEGA project No. 006ŽU-4/2019 Quality improving and innovation the subjects content continuity of Automated Production Systems study program to bachelor study programs of Mechanical Engineering Area

\section{References}

1. K. Semrád, J. Čerňan, Aplikácia CAX metód v systéme CREO. Technická univerzita v Košiciach, 125 pp (2015)

2. N. Cubonova, Utilization of genetic algorithms by the tool path programming. Annals of DAAAM for 2011 \& Proceedings of the 22nd international DAAAM symposium "Intelligent manufacturing \& automation: Power of knowledge and creativity". 22, 0063-0064 (2011)

3. N. Čuboňová, Genetic algorithms implemented for optimization of technological processes. Chosen applications of computer modelling in mechanical engineering. 157-181(2015)

4. N. Čuboňová, M. Michalco, Návrh optimalizácie nástrojových dráh s využitím genetických algoritmov. Technika: časopis o priemysle, vede a technike, 10, 46-47 (2012)

5. I. Kuric, V. Tlach, Z. Ságová, M. Císar, I. Gritsuk, Measurement of Industrial Robot Pose Repeatability. In MATEC Web of Conferences. 244, (2018)

6. T. Dodok, N. Cubonova, M. Cisar, I. Kuric, I. Zajačko, Utilization of strategies to generate and optimize machining sequences in CAD/CAM, Procedia Engineering, 192, 113-118 (2017)

7. M. Sága, M. Vaško, N. Čuboňová, W. Piekarska, Optimisation algorithms in mechanical engineering applications. Harlow: Pearson (2016)

8. N. Náprstková, Students Connecting to Production Problems Resolutions in CAD/CAM Area. 9TH International Scientific Conference: Engineering for Rural Development. 310-314 (2010) 